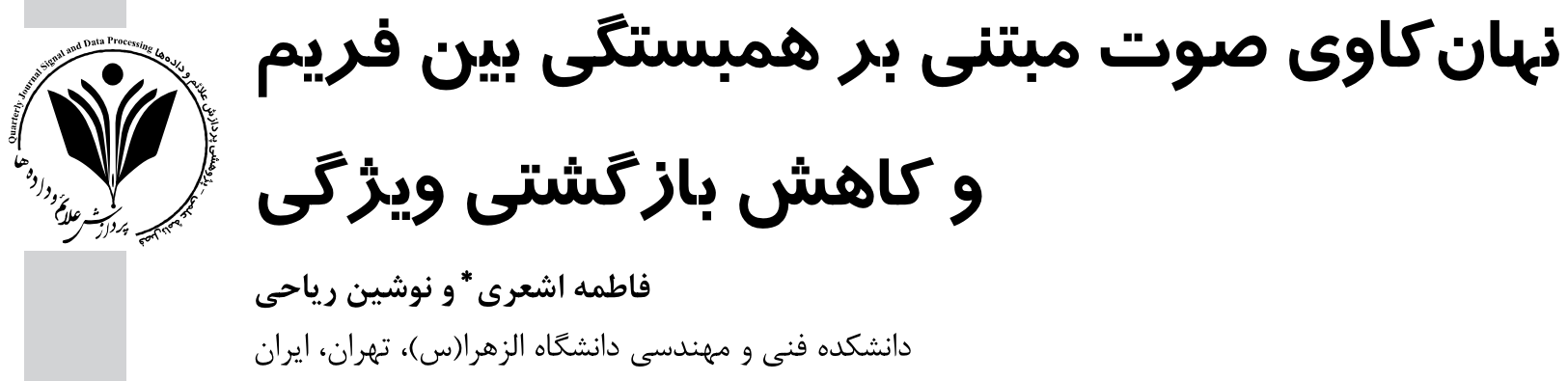

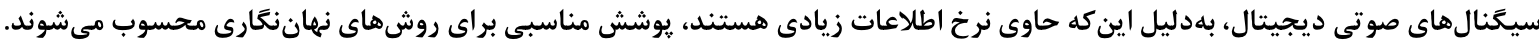

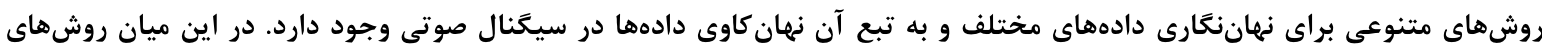

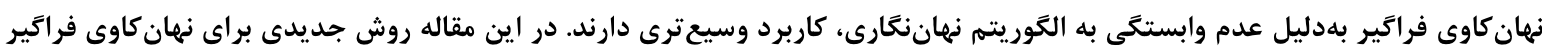

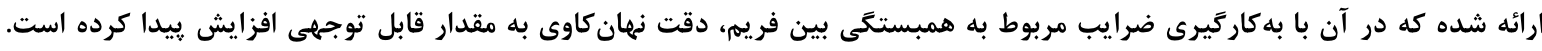

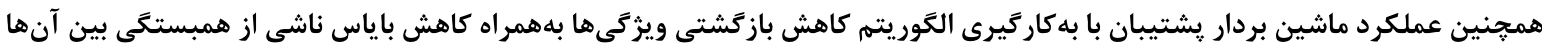

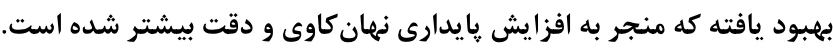
وازَّان كليدى: نهان نغارى، نهان كاوى، همبستكى بين فريم، كيستروم مل معكوس، كاهش ويزكى بازگشتى

\title{
Audio Steganalysis based on Inter-frame correlation and recursive feature elimination
}

\author{
Fatemeh Ashari* \& Nooshin Riahi \\ College of engineering, Alzahra University, Tehran, Iran
}

\begin{abstract}
Dramatic changes in digital communication and exchange of image, audio, video and text files result in a suitable field for interpersonal transfers of hidden information. Therefore, nowadays, preserving channel security and intellectual property and access to hidden information make new fields of researches naming steganography, watermarking and steganalysis. Steganalysis as a binary classification distinguish clean signals from stego signals. Features extracted from time and transform domain are proper for this classifier.

Some of steganalysis methods are depended on a specific steganography algorithm and others are independent. The second group of methods are called Universal steganalysis. Universal steganalysis methods are widely used in applications because of their independency to steganography algorithms. These algorithms are based on characteristics such as distortion measurements, higher order statistics and other similar features.

In this research we try to achieve more reliable and accurate results using analytical review of features, choose more effective of them and optimize SVM performance.

In new researches Mel Frequency Cepstral Coefficient and Markov transition probability matrix coefficients are used to steganalysis design. In this paper we consider two facts. First, MFCC extract signal features in transform domain similar to human hearing model, which is more sensitive to low frequency signals. As a result, in this method there is more hidden information mostly in higher frequency audio signals. Therefore, it is suggested to use reversed MFCC. Second, there is an interframe correlation in audio signals which is useful as an information hiding effect.

For the first time, in this research, this features is used in steganalysis field. To have more accurate and stable results, we use recursive feature elimination with correlation bias reduction for SVM.
\end{abstract}

Corresponding author

* *ويسنده عهرهدار مكاتبات 
To implement suggested algorithm, we use two different data sets from TIMIT and GRID. For each data sets,Steghide and LSB-Matching steganography methods implement with 20 and 50 percent capacity. In addition, one of the LIBSVM 3.2 toolboxes is sued for implementation.

Finally, the results show accuracy of steganalysis, four to six percent increase in comparison with previous methods. The ROC of methods clearly shows this improvement.

Keywords: steganalysis, steganography, Mel, SVM-RFE+CBR

هستند كه نهانكاوى فراكير ناميده مىشوند. الكوريتمهاى

نهان كاوى فراخير صوت بر اساس مشخصههايى همجون مُون معيار

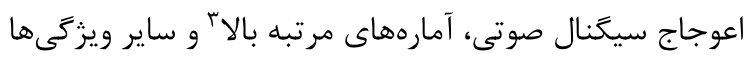

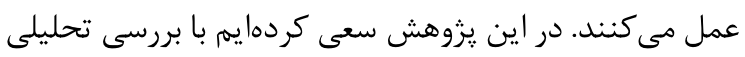

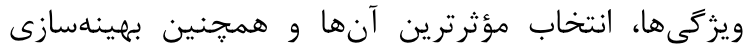

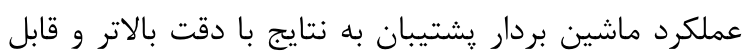
اعتمادترى دست ييدا كنيم.

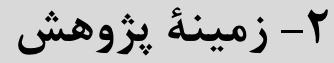

در سال ץ +. Ozer Y و همكارانش توزيع معيارهاى متنوع

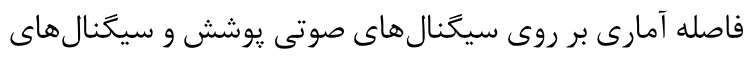

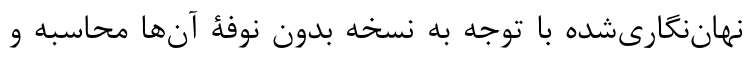

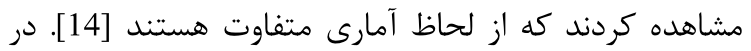
اين روش معيارهاى كيفيت صوت به كار مىرود تا حالات

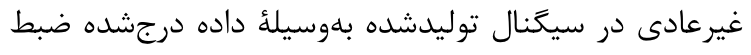

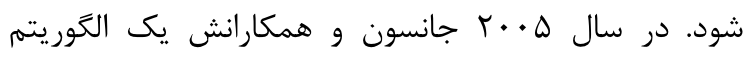

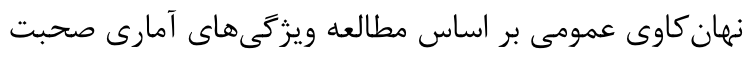
ضبطشده ارائه دادند [13].

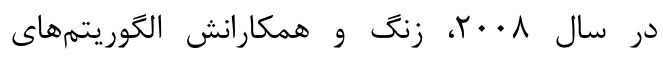

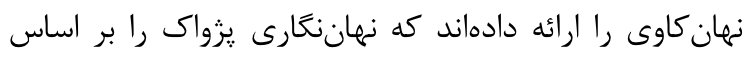

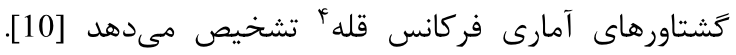

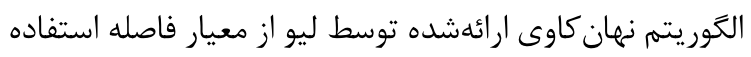

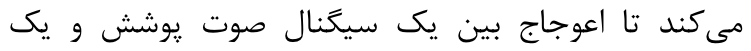

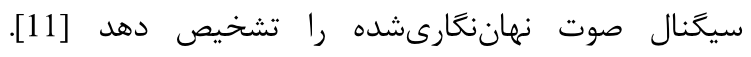
آمارههاى بهدستآمده بر اساس فاصله هاسدورفه ه بهعنوان

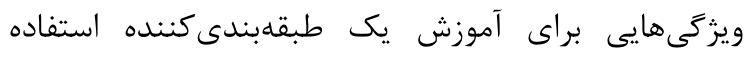

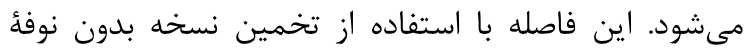

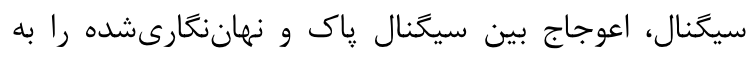

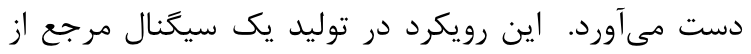

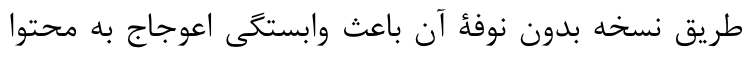

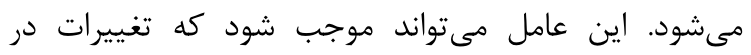

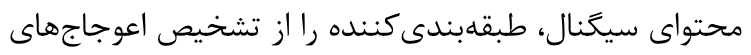

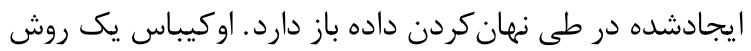

${ }^{3}$ Higher order statistics

${ }^{4}$ Peak Frequency

${ }^{5}$ Hausdorff distance
- (- مقدمه

افزايش روزافزون ارتباطات ديجيتال و تسهيل تبادل انواع فايلها اعم از تصوير، صوت، ويدئو و متن، بلوسيلئ ابزارهاى دون

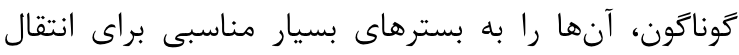

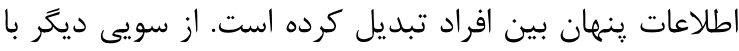

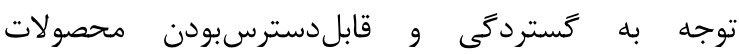
جندرسانهاى، لزوم حفظ حق مالكيت اثر افزايش يافته است.

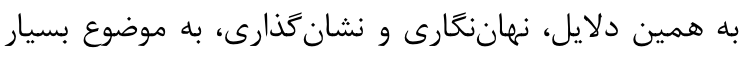

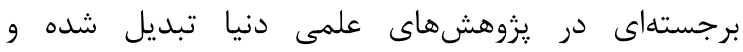

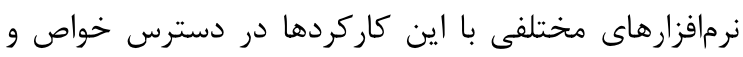

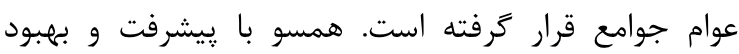
روشهاى نهاننگارى و نشان گذارى، نهان كاوى نيز به موضوع

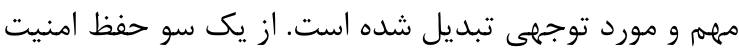

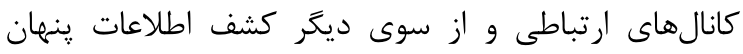

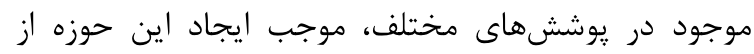
يزوهش هوجا است.

مسئله نهان كاوى درواقع يك مسئله طبقهبندى

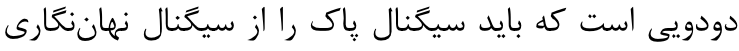

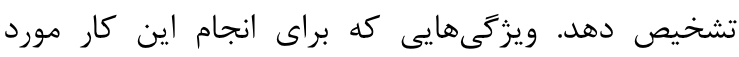

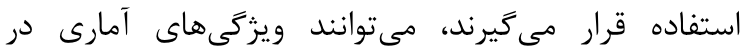
حوزههاى زمان و تبديل باشند. بهدليل شفافيت يك سيخنال

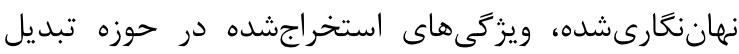

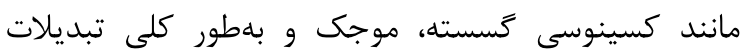

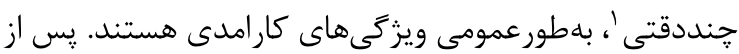

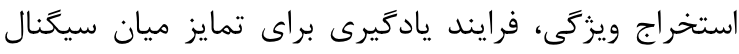

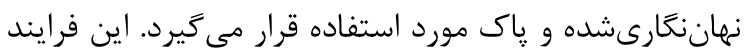

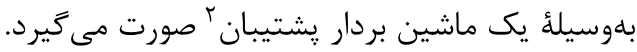

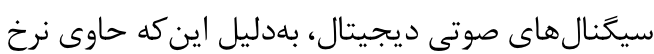
اطلاعات زيادى هستند، يوشش مناسبى براى روشهاى

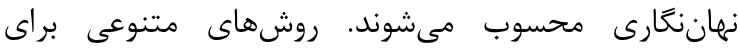

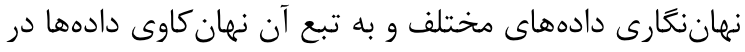

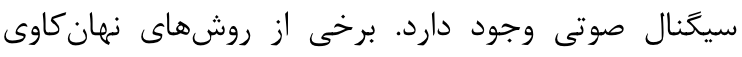

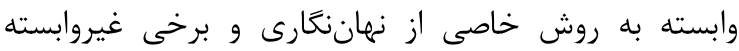

${ }^{1}$ Multi Resolution

${ }^{2}$ SVM 
شود. در ادامه هر يك از ويزگى هاى بيشنهادى بلهور مشروح توضيح داده خوهد شد.

\section{I - - ضر ايب كِيسستروم معكوس مل}

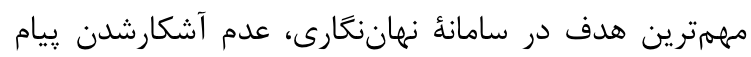

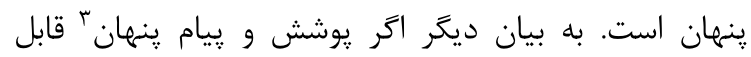

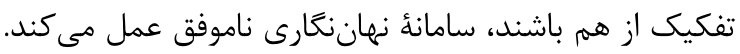

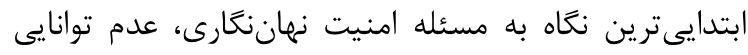
تشخيص آن توسط دستكاه شنوايى است. بنابراين براى يك إنى

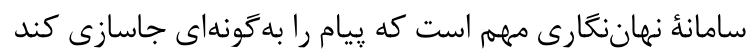

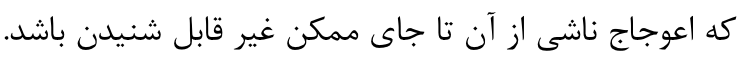

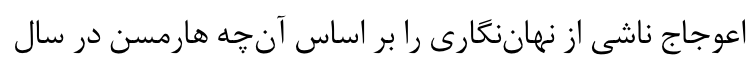

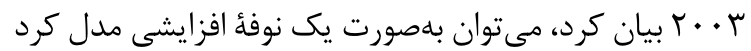

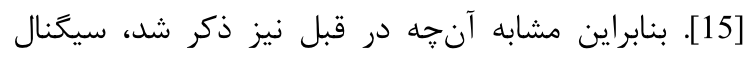

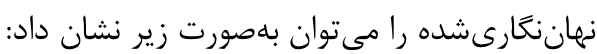

$$
S(t)=f(t)+\mathrm{e}(\mathrm{t})
$$

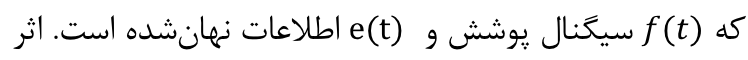
نهاننگارى يا بهعبارتى حضور نوفه در فركانس هاى بالا بيشتر

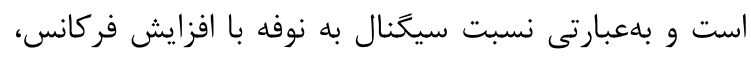
افزايش مىيابد. مقياس مل بهكونهاى تنظيم شده كه مشابه كوش انسان، بيشترين وضوح را در فركانسهای كمترين وضوح را در فر كانسهاى بالا دار دارد. از سوى ديكر اين بخش، مربوط به به فرانس دانس بارد بالاى

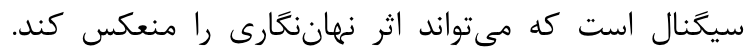

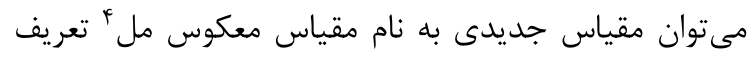

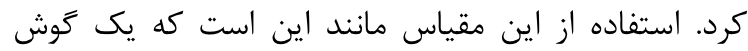

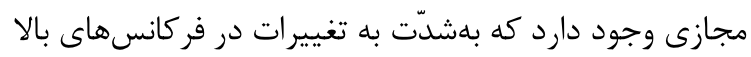

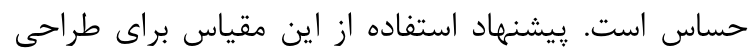

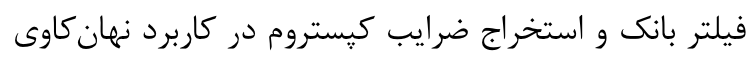

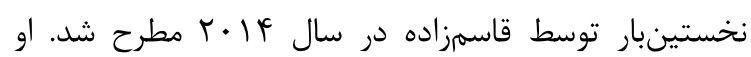
مقايسهاى بين كارامدى ضرايب مل و معكوسى مل در كاربرد

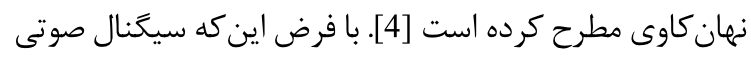
داراى فر كانس نمونهبردارى Fs باشد، مقياس معكوس مل بر براى

$$
\text { فركانس f بر حسب هرتز عبارت است ازئ }
$$

$$
f_{\text {rmel }}=1127 \times \ln \left(1+\frac{\frac{F_{S}}{2} f}{700}\right)
$$

نهان كاوى صوت بر بايه معيارهاى اعوجاج مستقل از محتوا

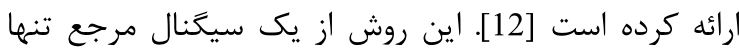

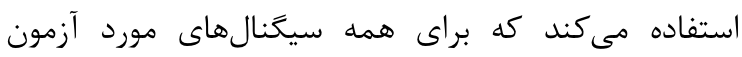

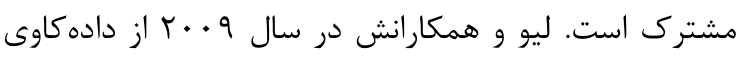

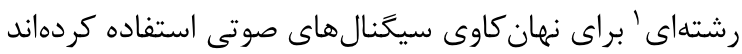

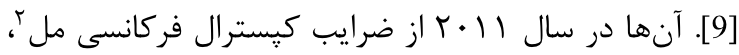

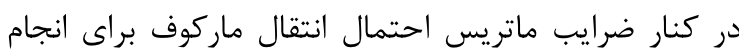

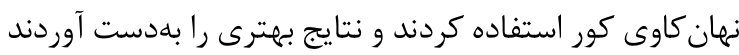

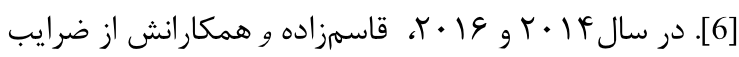

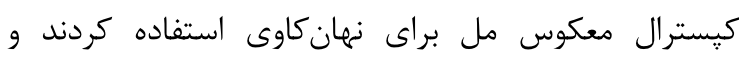

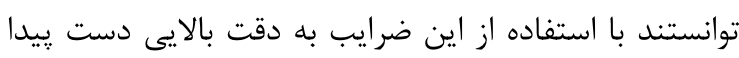

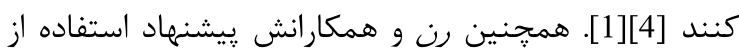

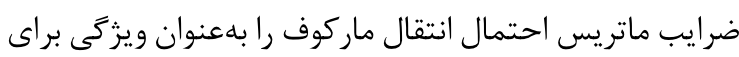
نهان كاوى صوت دادهاند [2].

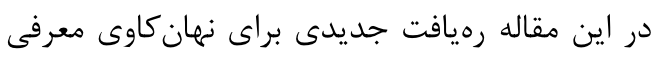

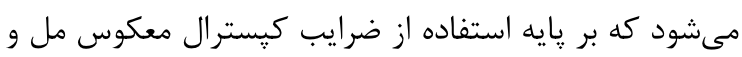
ضرايب همبستگى بين فريم براى مشتق دوم سيخنال است.

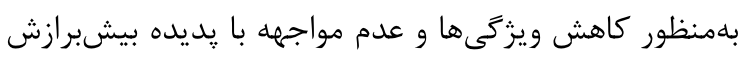

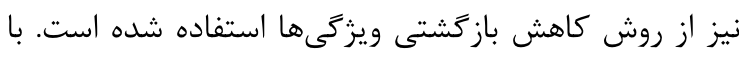

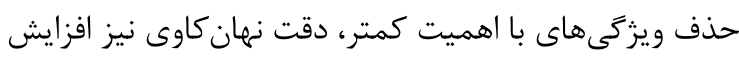

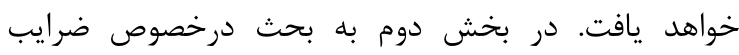

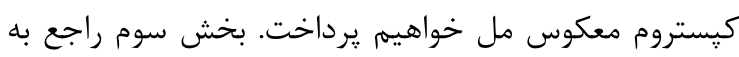

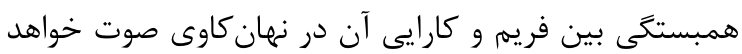

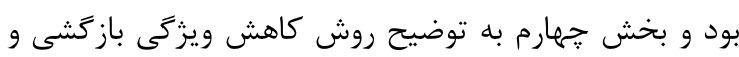

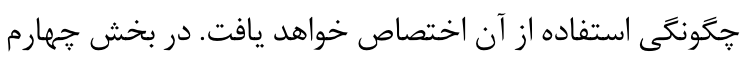
آزمايشهاى صورتكرفته و نتايج حاصل از آن آن ارائه خواهد

\section{r- روش بيشنـهادى}

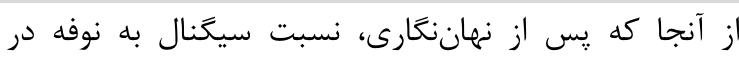

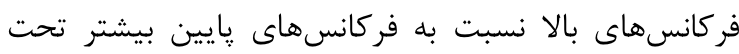

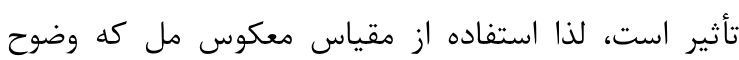
بيشترى در فر كانسهاى بالا دارد، در كارايى نهان كاوى مؤثرتر

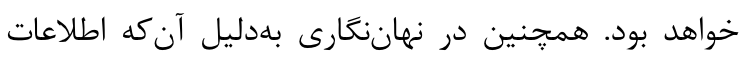

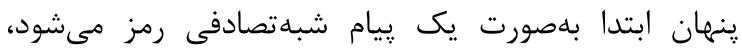

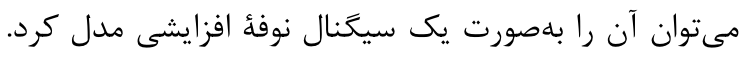

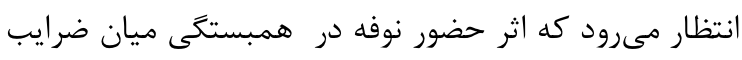

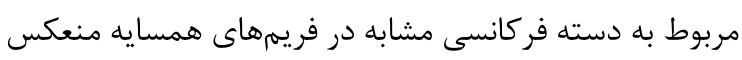

${ }^{1}$ Stream data mining

${ }^{2}$ Mel Frequency Cepstral Coefficient 
معادله زير نحوه محاسبه همبستخى بين ضرايب مل

فريمهاى همسايه را نشان مىدهد:

$r\left(M F C C s_{i}, M F C C s_{i+k}\right)=$

$$
\frac{\sum_{n=1}^{N-1}\left(C_{(i, n)}-\bar{C}_{i}\right)\left(C_{(i+k, n)}-\bar{C}_{i+k}\right)}{\sqrt{\sum_{n=1}^{N}\left(c_{(i, n)}-\bar{C}_{i}\right)^{2} \sum_{n=1}^{N}\left(C_{(i+k, n)}-\bar{C}_{i+k}\right)^{2}}}
$$

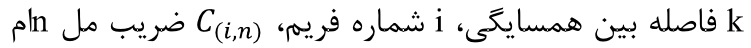
فريمز و N تعداد كل فريمهاست.

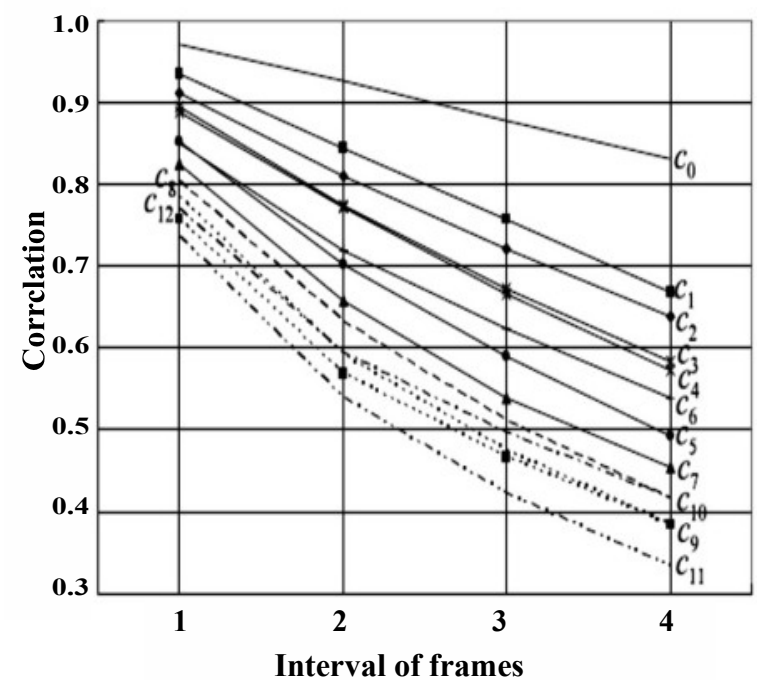

MFCC شكل - (Y) (شبستكَى بين فريم براى ضرايب (Figure-2): interframe Correlation for MFCC Coefficients

شكل (Y) همبستگى هر بردار ضرايب مل را برحسب فاصله

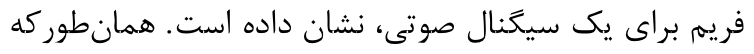
انتظار مىرود با افزايش مقدار k ميزان همبستخى كاهش

اين همبستخى بين فريم با درنظر كرفتن هميوشانى در

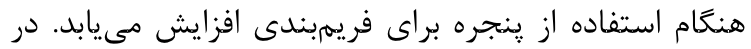

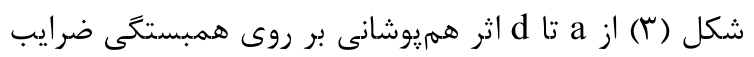
كيسترال نشان داده شده است.

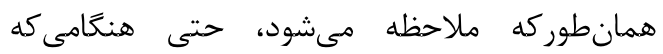

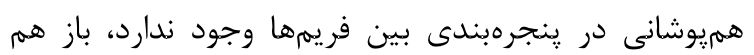

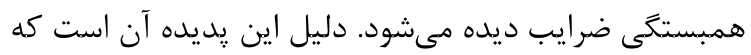

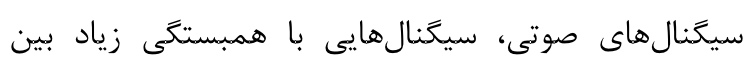
فريممها هستند.

در اين مقاله از ميانكين وج ضريب معكوس مل موجود

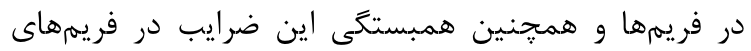
همسايه بهعنوان ويزّى در طبقلبندى استفاده شده است.
بر اساس اين مقياس، مجموعهاى از فيلترهاى مثلثى ساخته

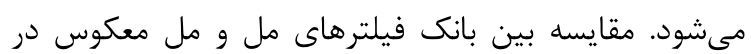
شكل ( ) نشان داده شده است.
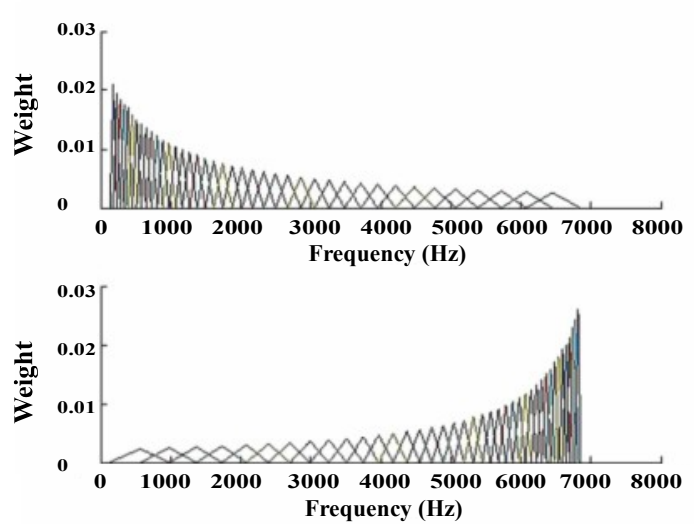

(شكل - (): مقايسه فيلتربانك مل (شكل بالا) و معكوس مل (شكل

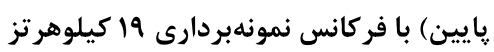

(Figure-1): Comparison between Mel and Reversed Mel FilterBank

فرآيندى بهطوردقيق مشابه آنجه در استخراج ضرايب

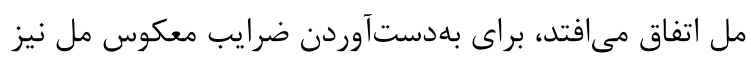

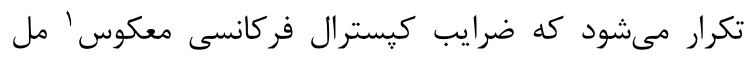

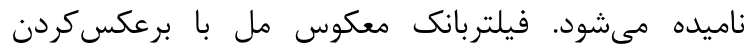

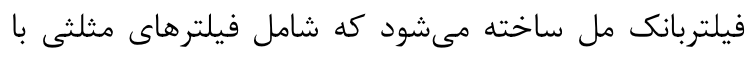

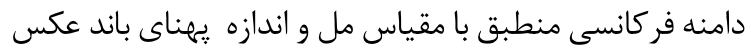

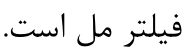

بهكار كيرى ويزگى هايى كه اطلاعات مربوط به دستخاه

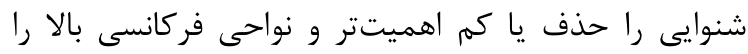

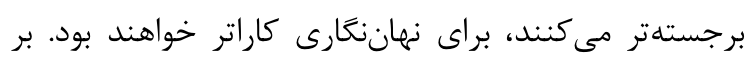

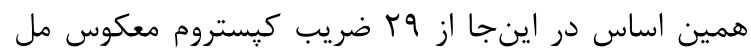
بلهعوان ويزگى استفاده شده.

\section{Y-r - همبستخى بين فريمها}

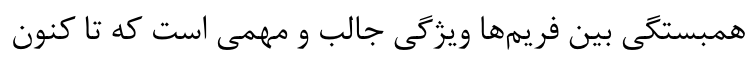
از آن در حوزه نهانكاوى صوت استفاده نشده است. حضو حضور

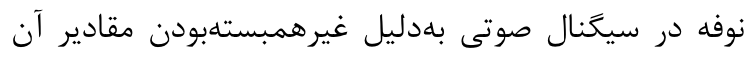
موجب كاهش همبستى موجود در فريمهاى همسايه

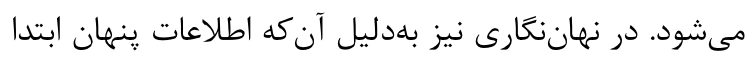

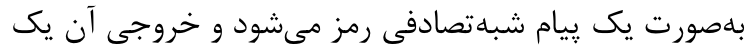
رشته شبهتصادفى است، مىتوان آن را بهصورت يك سيكنال

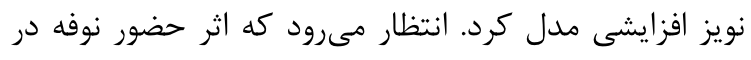
همبستخى ميان ضرايب مل مربوط به دسته فر كانسى مشابه

در فريمهاى همسايه منعكس شود.

${ }^{1}$ Reversed Mel Frequency Cepstral Coefficients 
طبقدبندى تعدادى از ويزَگىهاى با رتبه پايينتر در فهرست

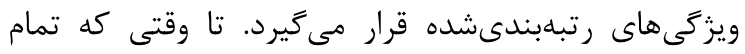

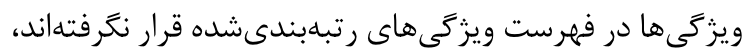
طبقلهبندى به روش ماشين بردار يشتيبان انجام مى

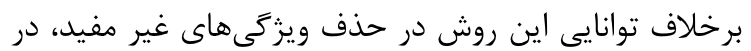

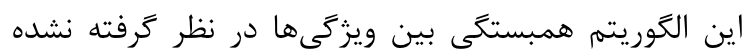

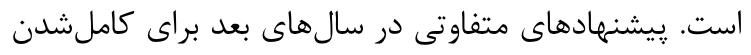

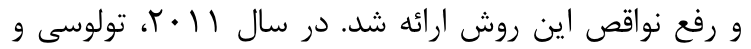

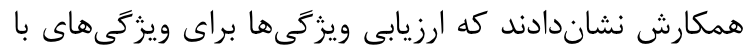

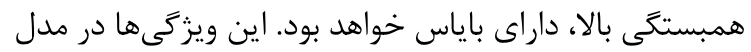

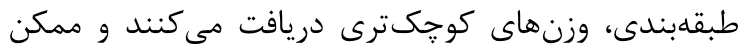

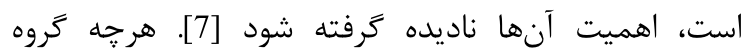

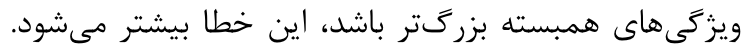

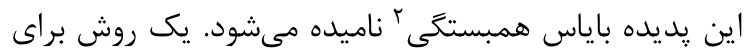

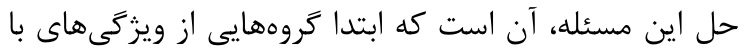

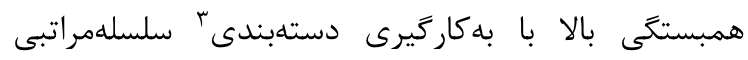

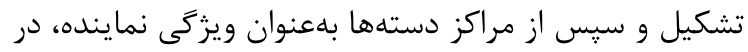

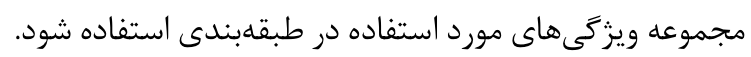

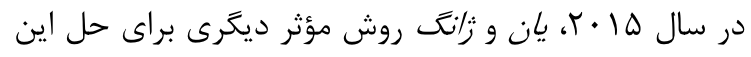

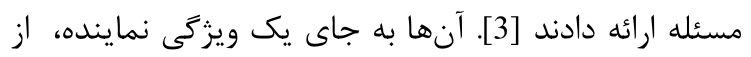
يك فهرست ويزگى بازمانده" استفاده مى كنند. ابتدا كاهش

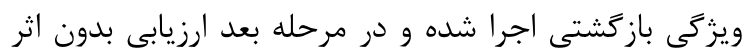

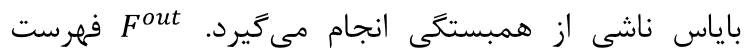

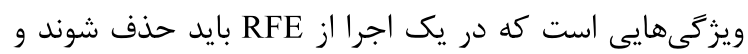

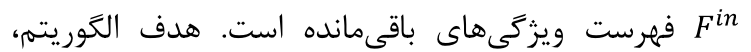

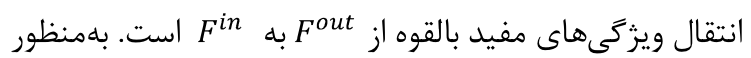

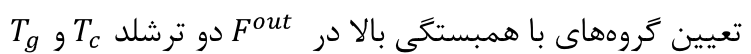

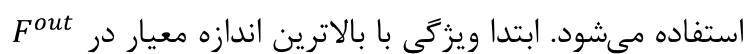

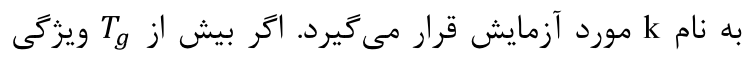

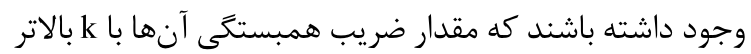
از

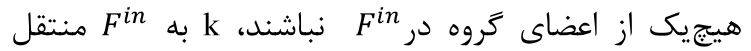

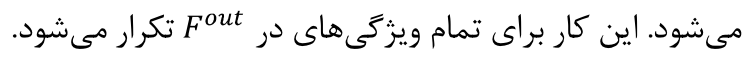

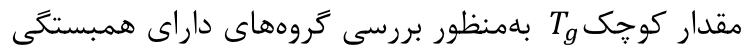

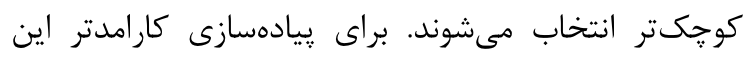

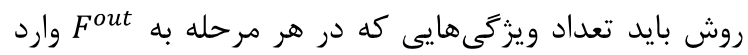

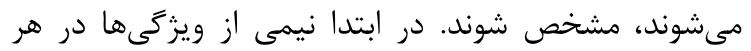

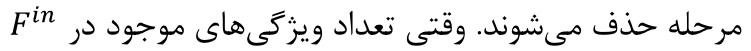

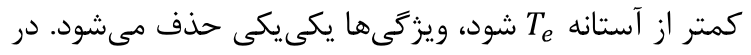

${ }^{2}$ Correlation Bias (CB)

${ }^{3}$ Clustering

${ }^{4}$ Surviving

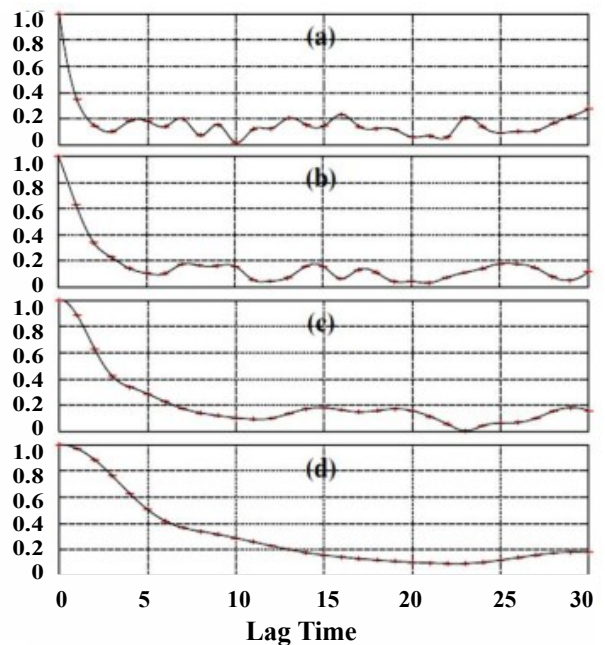

(شس - I). اساره معبسسى بين حريمم براى هـهرمين باند

فر كانسى در حالتى كه در a) هيج هميوشانى وجود ندارد، b )

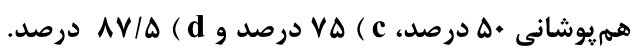

(Figure-3): Interframe Correlation for forth frequency band for a) without correlation b) $50 \%$ correlation c) $\mathbf{7 5 \%}$ correlation d) $87.5 \%$ correlarion

\section{r-r- كاهش ويزگى بازگشتى با استفاده از كاهش باياس در همبستكى}

يافتن روشى براى كاهش بعد فضاى ويزَّى و غلبه بر مشكل

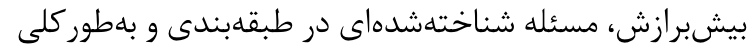

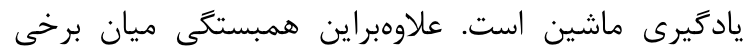

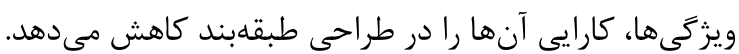

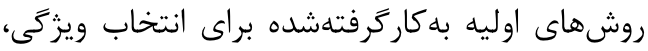

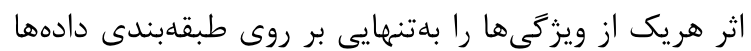

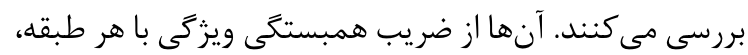

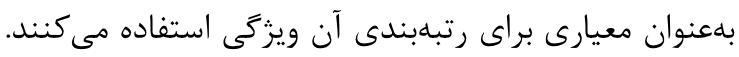

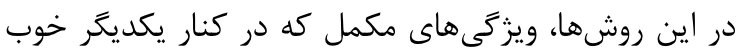

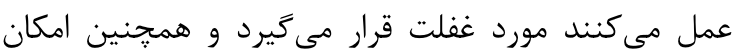

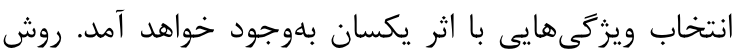

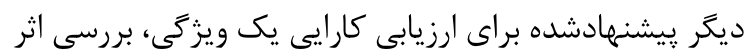

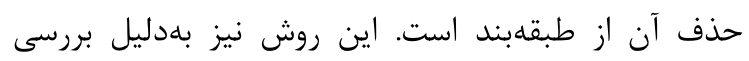

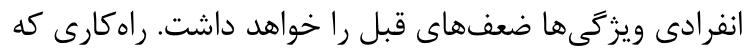

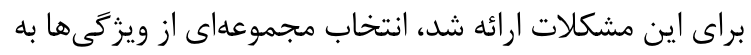

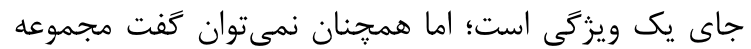

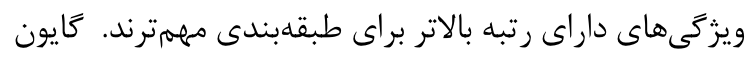

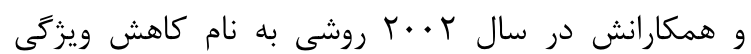

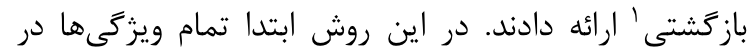

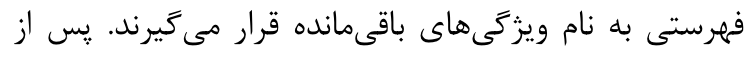

${ }^{1}$ Recursive Feature Elimination 


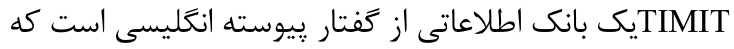
توسط شركت TI و دانشعاه MIT تهييه شده و اداره استاندارد

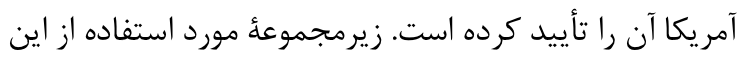

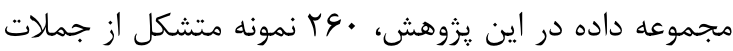
دمكانه بيانشده از عب كَينده است. بر روى هر يك از مجموعههاى داده، نهاننخارى به

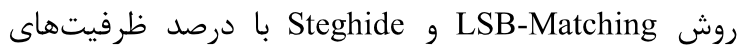

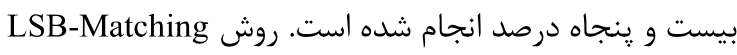

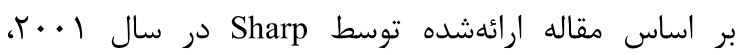
ييادهازى شده است [13]. Steghide يكى از ابزارهاى معتبر

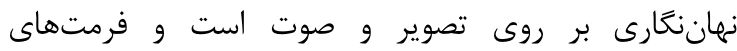

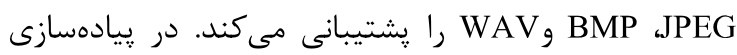
حاضر از نسخه ا. ه ه. • آن استفاده شده است.

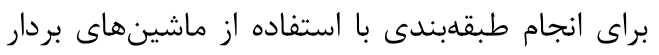

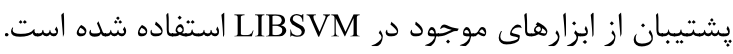

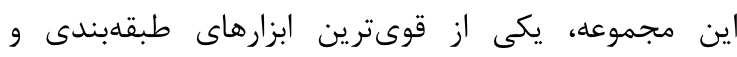

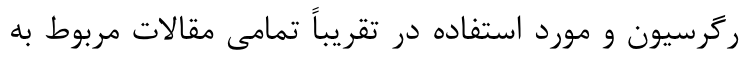

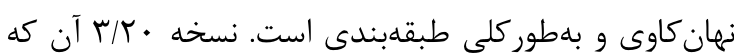

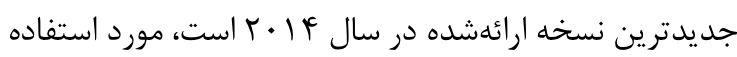

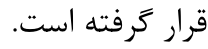

\section{ץ-F- نتايج آزمايشهاى و تحليل بهبودهاى

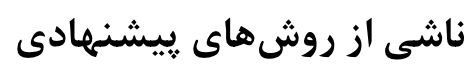

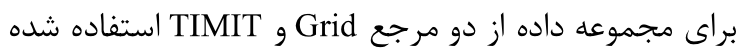
است. براى هر يك از دو مرجع كمينه، بيشينه و ميانكين دانين يِيجيدگى بر اساس فرمول يِيشنهادى ليو محاسبه شده است.

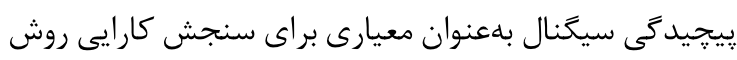

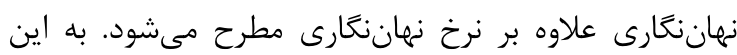

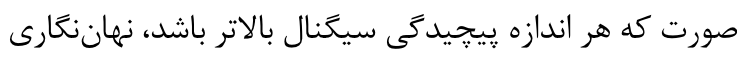

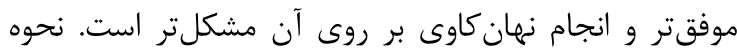

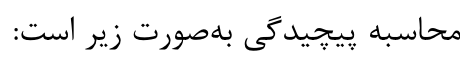

$C(f(t))=\frac{\frac{1}{N-2} \sum_{t=0}^{N-1}\left|D_{f}^{2}(t)\right|}{\frac{1}{N} \sum_{t=0}^{N-1}|f(t)|}$

بر اساس دستهبندى انجامشده در مقاله ليو، جهار كروه سيكنال با يِيجيدكىهاى مختلف مورد بررسى قرار كرفته

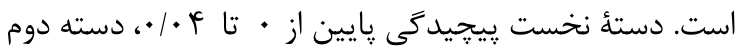

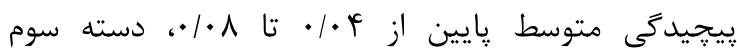

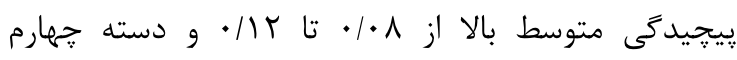

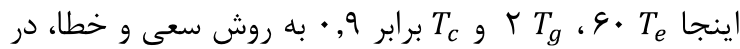

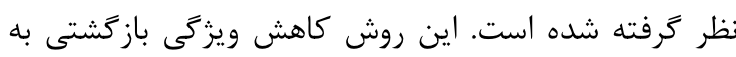
همراه كاهش باياس همبستكى' ناميده مى شود.

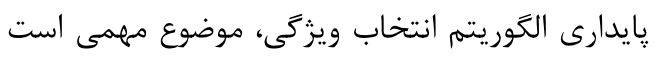
كه درهميناواخر در يزوهشها به آن يرداخته شده است.

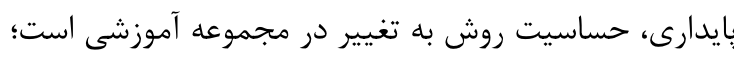

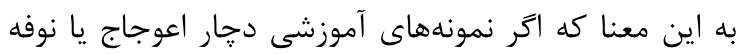

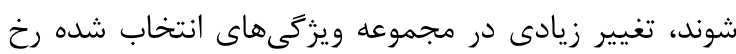
ندهد.

اندازٔ تفاوت بين دو زيرمجموعهُ انتخابشده رامىتوان

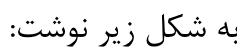

$S(A, B)=\frac{|A \cap B|}{|A \cup B|}$

اين مقدار بين صفر و يك قرار دارد كه صفر به معنى عدم

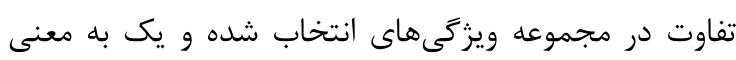
عدم اشتراك در اين موجموعه است. براى ارزيابى پايدارى إنى

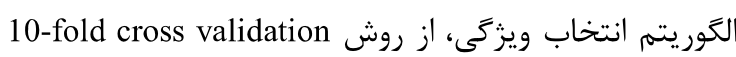
استفاده مىشود. در هر مرحله بهطور تصادفى تعدادى از از

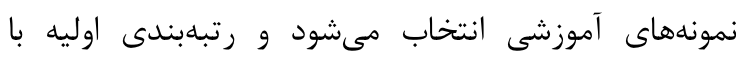

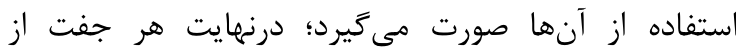

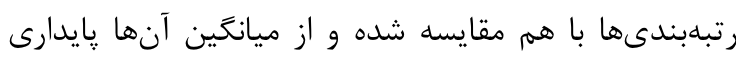
نهايى به دست مى آيد. طبق بررسى انجامشده توسط

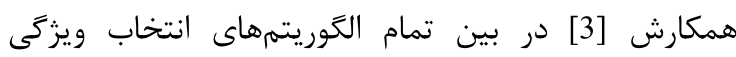

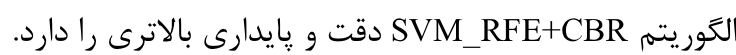

\section{F - شبيهسازى و نتايج روش ييشنهادى

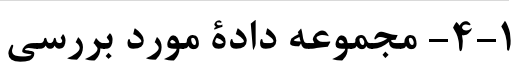

براى ييادهازى و استخراج نتايج از دو مجموعه داده استفاده

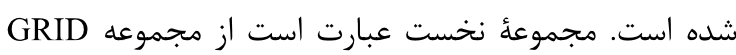

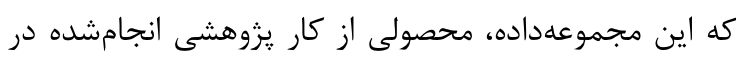

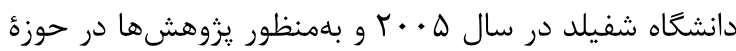

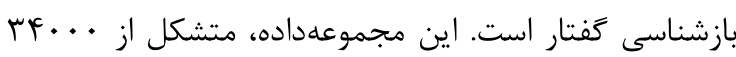

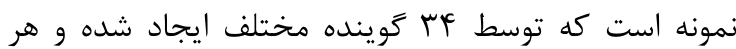

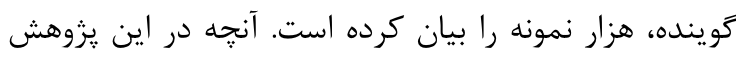

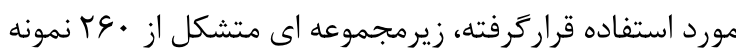

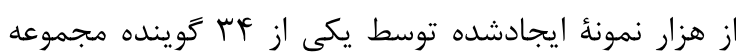

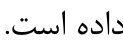

مجموعه ديكر TIMIT است. اين مجموعه داده نيز از مجموعههاى بسيار معروف و كارامد براى يردازش كَفتار است.

${ }^{1} \mathrm{SVM}-\mathrm{RFE}+\mathrm{CBR}$ 


$$
\begin{gathered}
\delta(F(u)=m, F(u+1)=n)= \\
\left\{\begin{array}{c}
1, \text { if } F(u)=m, F(u+1)=n \\
0, \text { Otherwise }
\end{array}\right.
\end{gathered}
$$

يس از ساخت ماتريس هر يك از اجزاى آن بهعنوان

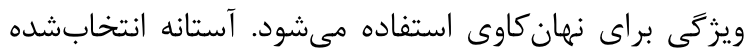

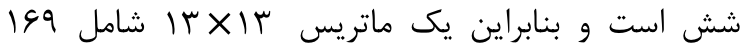
ويزّكى بلهدست خواهد آمد.

در اين مقاله، ويزگى هاى كارامدترى ارائه شده كه اهد موجب افزايش دقت و يايدارى نهانكاوى شده است. ضرايب

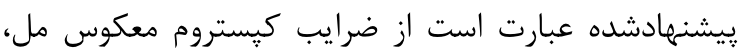
ضرايب معكوس فيلترشده مل و همبستگكى بين فريم. ضرايب

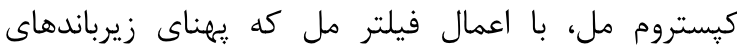
فركانسى آن با مقياس مل محاسبه مى ميود، بر روى اندازه

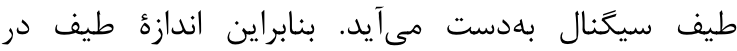

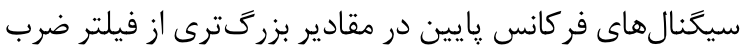
و با وضوح بيشترى بررسى خواهد شد. از سوى ديخر ضرايب معكوس مل همين عملكرد را براى بخش فركانس بالاى

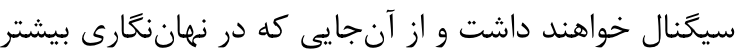
تغييرات در باندهاى فركانس بالا اتفاق مى افتد، انتظار مى ميرود ويزگ كى هاى مهرمترى براى نهان كاوى باشند.
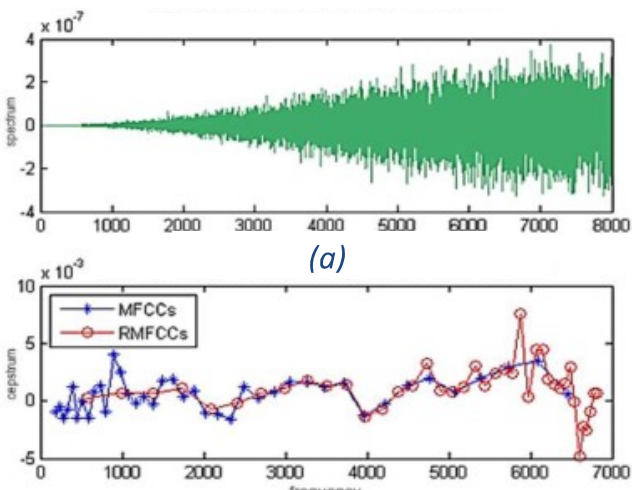

(b)

(شكل - (F): a : تفاوت اندازه طيف سيخنال ياك و

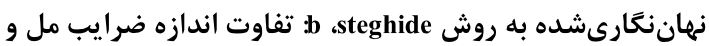

معكوس مل براى اين دو سيخنال

(Figure-4): a:Difference between clear and stego signal with steghide method ,b: Difference between Mel and reversed Mel coefficients for these signals

شكل (F) نتايج اعمال فيلتربانك مل و معكوس مل بر

روى يك سيخنال نهان نغارى شده را از مجموعه TIMIT نشان

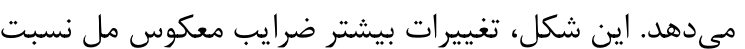
به ضرايب مل در اثر اعمال الكوريتم نهاننگارى را بهوضوح بيان مى كند.

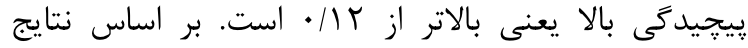
بلدستآمده در آن مقاله، دقت بلهدستآمده براى طبقهبندى بالهي

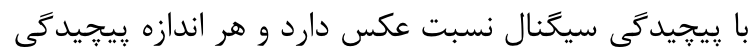
بالاتر برود دقت طبقهبندى كاهش مىيابد.

براى سيگنالهاى موجود در دو مرجع GRID و و

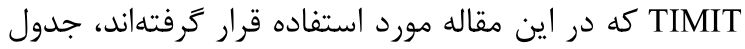

$$
\text { (1) ميزان يِجيدگى را نشان مىدهد. }
$$

(جدول -1): ميزان بيجِيدكى سيخنال در مراجع داده

(Table-1): Complexity of signal for different data bases

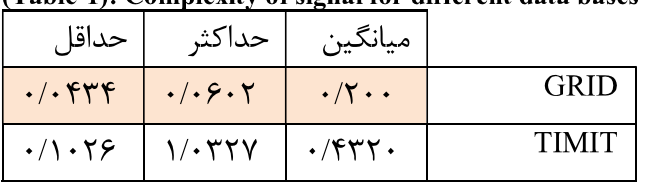

بر اساس دستهبندى ذكرشده در بالا، سيگنالهاى

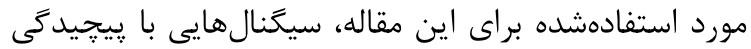

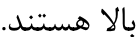

براى هر يك از دو دسته داده، نهاننگارى با روشهاى و و و با ظرفيتهاى بيست و ينجاه

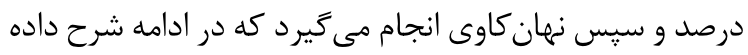
خواهد شد.

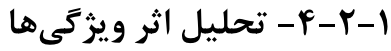

تا كنون ويزگى هاى متفاوتى در حوزه نهان كاوى مطرح شده

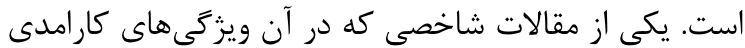
مطرح و بهعنوان مرجع در بسيارى از يزوهشهاى معتبر اين معن ان

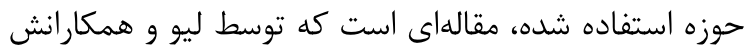
مطرح شده است [6]. در اين مقاله از ضرايب ماتريس احتمال

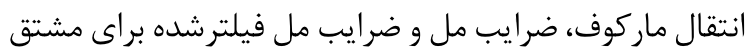
دوم سيخنال بهعنوان ويزگى استفاده شده است.

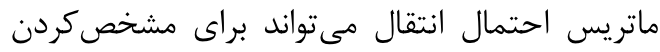
فرايند اتفاقى ماركوف استفاده شود. در اين ماتريس، احتمال انتقال بين دو عنصر همسايه نشان داده مىشود. اتر يك مك سيخنال صوتى با $(t=0,1,2, \ldots, N)$ (t) ماتريس احتمال انتقال ماركوف براى مشتق دوم سيخنال : $D_{f}^{2}(t)(t=1,2, \ldots, N-2)$

$M_{D_{f}^{2}}(i, j)=\frac{\sum_{t=1}^{N-3} \delta\left(D_{f}^{2}(t)=i, D_{f}^{2}(t+1=j)\right.}{\sum_{t=1}^{N-3} \delta\left(D_{f}^{2}(t)=i\right)}$

كه $\delta$ بdصورت زير تعريف مىشود: 

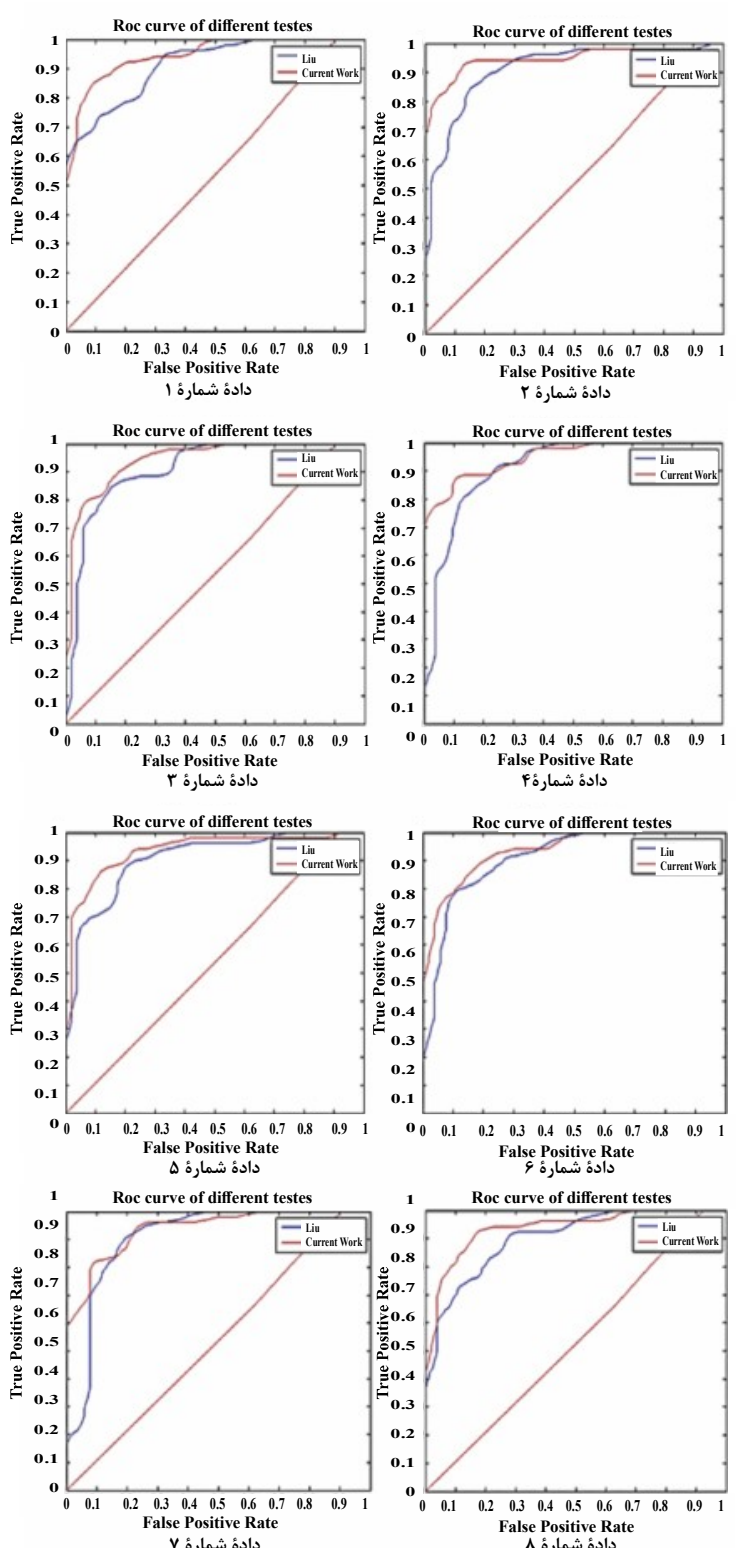

False Positive Rate

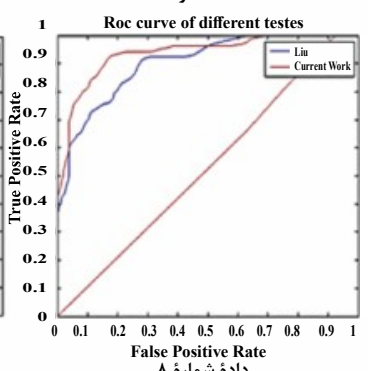

(شكل - D): منحنى هاى ROC دو روش

(Figure-5): ROC Curves for both Approaches

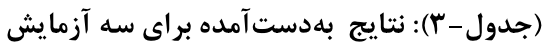

(Table-3): Results for three Experiments

\begin{tabular}{|c|c|c|c|c|}
\hline مجموعه & ماده ا & ماده r مجمه & ماده بـ & داده Fموعه \\
\hline روش & 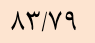 & Y & r r & r \\
\hline ليو &.$/ 91$ & $\cdot 19$ & $\cdot / 9$ & .1911 \\
\hline روش & $V / V$ & $\Lambda V / q F$ & $V / 90$ & $N / T)$ \\
\hline بيشنهادى &.$/ 948$ &.$/ 94 \mathrm{~V}$ & .1940 & . $/ 949$ \\
\hline كاهش & er/i & $1 / 0$ & N/Va & $\Lambda / r$ \\
\hline ويثكى &.$/ 9 \Delta$. &.$/ 9 \Delta F$ &.$/ 9 \Delta 1$ & $.19 \Delta \Delta$ \\
\hline
\end{tabular}

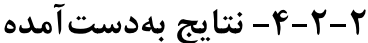

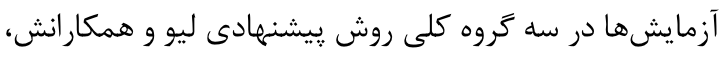
روش ييشنهادى در اين مقاله با استفاده از ويزگكىهاى

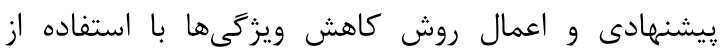

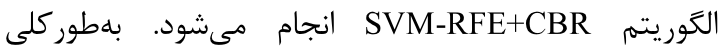

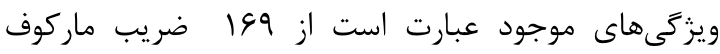
MKV

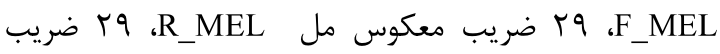
معكوس مل فيلترشده R_F_MEL و به اندازه تعداد فريمها

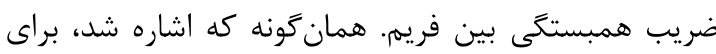

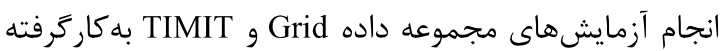

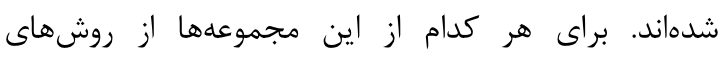

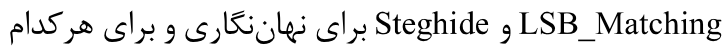

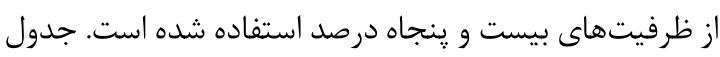

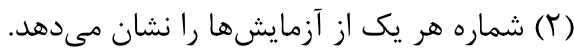

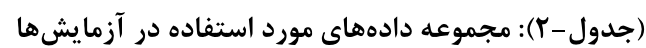

\begin{tabular}{|c|c|c|c|c|}
\hline مجموعه & $\begin{array}{l}\text { grid } \\
\text { lsbmch } \\
20 \%\end{array}$ & $\begin{array}{l}\text { grid } \\
\text { lsbmch } \\
50 \%\end{array}$ & $\begin{array}{c}\text { grid } \\
\text { stghd } \\
20 \%\end{array}$ & $\begin{array}{c}\text { Grid } \\
\text { stghd } \\
50 \%\end{array}$ \\
\hline شماره & 1 & r & $r$ & f \\
\hline مجموعه & $\begin{array}{c}\text { timit } \\
\text { lsbmch } \\
20 \%\end{array}$ & $\begin{array}{c}\text { timit } \\
\text { 1sbmch } \\
50 \%\end{array}$ & $\begin{array}{c}\text { timit } \\
\text { stghd } \\
20\end{array}$ & $\begin{array}{l}\text { Timit } \\
\text { stghd } \\
50 \%\end{array}$ \\
\hline شماره & $\Delta$ & \& & V & $\wedge$ \\
\hline
\end{tabular}

نمودارهاى شكل (a)، منحنى ROC روش ليو و روش يشينهادى را با هم مقايسه مى كند.

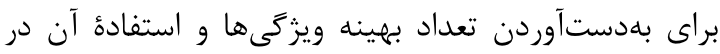

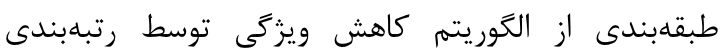
بهدستآمده از روش الز لهن

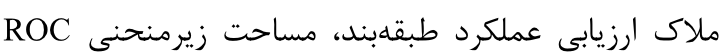

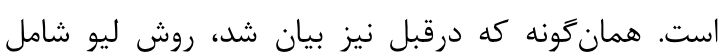
ضرايب ماركوف و مل، روش بيشنهادشده در اين مقاله شامل دئل

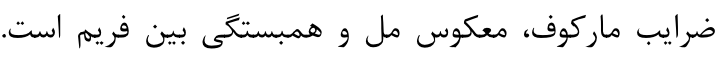

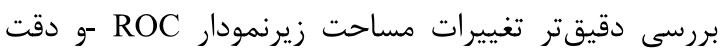

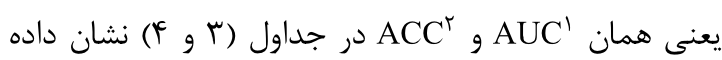
شده است. سطرهاى سفيد نشاندهندة درصد دقت و سطرهاى

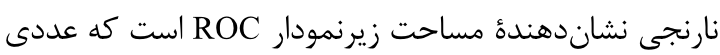

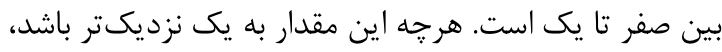
طبقدبند بهتر عمل كرده و نهان كاوى موفقترى صورت خور خواهد كرفت.

\footnotetext{
${ }^{1}$ Area Under Curve

${ }^{2}$ Accuracy
} 
با توجه به قرارداشتن سيخنالهاى مورد آزمايش در

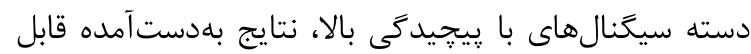

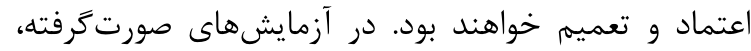

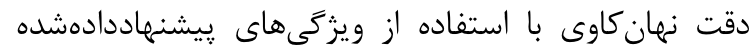
جهار تا شش درصد افزايش ريدا مى كند. مقايسه نمودارهاى ني

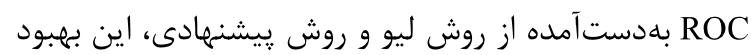
را بهوضوح نشان مى بلهند.

\section{6- References}

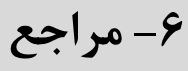

[1] Ghasemzadeh, H. Tajikkhas, M. Khalilarjmandi, H. "Audio Steganalysis based on psychoacoustic model of human hearing". (2016) ELSEVIER, Signal Processing Letters, Vol. 51, Pages 664-672.

[2] Ren, Y. Xiong, Q. Wang, L. "Steganalysis of AAC using calibrated Markov model of adjacent codebook". (2016) IEEE International Conference on Acoustica, Speech and Signal Processing.

[3] Yan, Ke. Zhang, David. "Feature selection and analysis on correlated gas sensor data withrecursive feature elimination". (2015) Elsevier, Sensors and Actuators B 212. Pages 353-363.

[4] Ghasemzadeh, H. Khalil Arjmandi, M. "ReversedMel Cepstrum Based Audio Steganalysis". (2014) IEEE 4th International eConference on Computer and Knowledge Engineering.

[5] Yang, Y. et.al. "An inter-frame correlation based error concealment of immittance spectral coefficients for mobile speech and audio codecs". (2014) IEEE International Conference on High Performance Computing and Communications.

[6] Liu, Q. Sung, A. Qiao, M. "Derivative-Based Audio Steganalysis". (2011) ACM Transactions on Multimedia Computing, Communications and Applications, Vol. 7, No. 3, Article 18.

[7] Tolosi, L. Lengauer, Th. "Classification with correlated features: unreliability of feature ranking and solu-tions". (2011) Data and text mining. Publ-ished by Oxford University Press. Vol. 27, Pages 1986-1994.

[8] Liu, Q. Sung, A. Qiao, M.’Temporal DerivativeBased Spectrum and Mel-Cepstrum Audio Steganalysis". (2009) IEEE Transaction on information forensics and security, Vol. 4, No. 3.

[9] Liu, Q. et al. "Novel Stram Mining for Audio Steganalysis". (2009) ACM International Conference on Multimedia, Pages 95-104.

[10] Zeng, W. et al. "An Algorithm of Echo Steganalysis based on Power Cepstrum and Pattern Classification". (2008) International Conference
(جدول - ( ) نتايج بهدست آمده براى سه آزمايش

(Table-4): Results for three Experiments

\begin{tabular}{|c|c|c|c|c|}
\hline مجموعه & داده هوعه & مجموعه & مجموعه & مجموعه 1 داده \\
\hline \multirow{2}{*}{ روش } & $\Lambda F / q F$ & $\Lambda T / \pi)$ & $\Lambda r / \cdot 1$ & $\Lambda 1 / V V$ \\
\hline & $\cdot 19 \cdot \Delta$ & $\cdot / 9 \cdot V$ & $\cdot 19 \cdot 9$ & $\cdot / 9 \cdot r$ \\
\hline \multirow{2}{*}{ بيشنهادى روش } & $\Lambda \& \mid \cdot r$ & $\Lambda \varepsilon / \mathcal{F}$. & $\Lambda \varphi / 4 \varphi$ & $\Lambda \Delta / \vee \cdot$ \\
\hline & . &.$/ 948$ & ./949 & • \\
\hline \multirow{2}{*}{ ويزگ كاهش } & $\wedge \vee / \Delta \cdot$ & $\Lambda \notin \mid \& Y$ & $\Lambda \mathrm{V} / \Lambda \Lambda$ & $\Lambda V / \mathcal{F}$. \\
\hline & -lafF & - / QFF & . /9FT & - IQFF \\
\hline
\end{tabular}

همانطور كه رفتارِ تاحدودى ثابت ويزگَىها در جدول

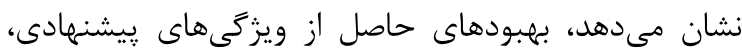

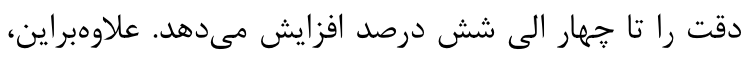

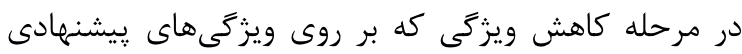

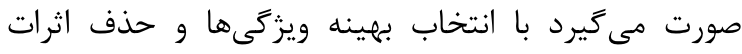
نامطلوب ويزگى ها بر روى يكديكر، دقت الكوريتم افزايش ييدا

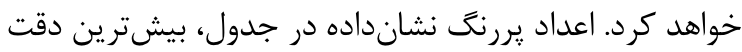
را در طبقهبندىهاى انجامشده نشان ميدهد.

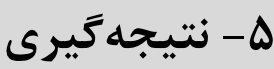

يكى از مهمترين روشهايى كه براى نهان كاوى در سالهاى

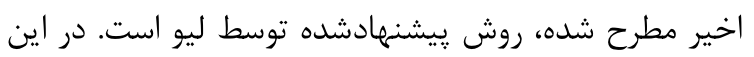
روش، از ضرايب ماتريس انتقال ماركوف و ضرايب كيستروم رئنس

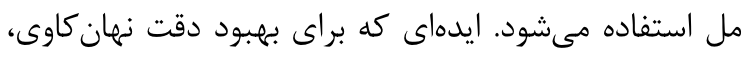

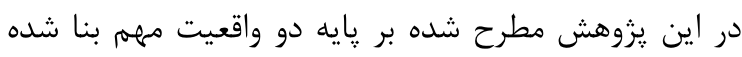

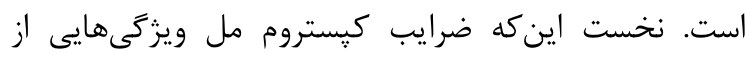
سيخنال را در حوزه تبدبل بر مبناى مدل شنوايى انسان

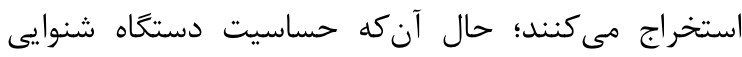
انسان، در فركانسهاى يايين بيشتر از فركانسهاى هاى بالا است.

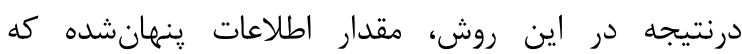
بهطورعمومى در فر كانسهاى بالا بيشتر حضوردارند، مورد دون

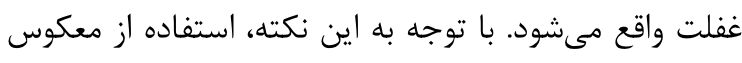

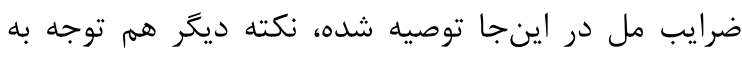

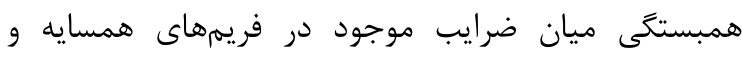

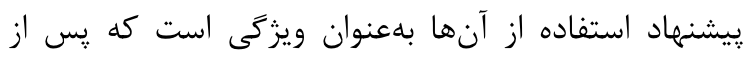

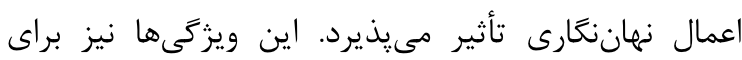
نخستينبار در زمينه نهان كاوى صوت مورد استفاده قرار

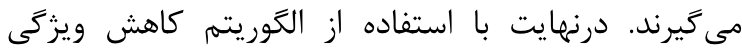
بازگشتى، دقت به ميزان قابل توجهى افزايش خواهد يافت. 


$$
\begin{aligned}
& \text { عضو هيئت علمى و استاديار گروه مهندسى كامِيوتر دانشكده }
\end{aligned}
$$

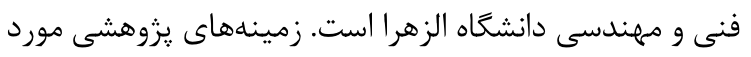

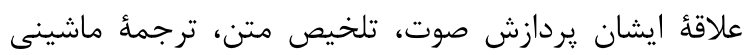

$$
\begin{aligned}
& \text { خودكار و يردازش سيكنالهاى بيولوزيك است. } \\
& \text { نشانى رايانامةٔ ايشان عبارت است ازئ }
\end{aligned}
$$

nriahi@alzahra.ac.ir on Information and Automation, Pages 16671670 .

[11] Liu, Y. el al. "A Novel Audio Steganalysis based on Higher-Order Statistics of Distortion Measure with Hausdroff Distence". (2008) Lecture Notes in Computer Science, Vol. 5222, Pages 487-501.

[12] Ismail Avcibas,"Audio Steganalysis With Content-Independent Dis-tortion Measures". (2006) IEEE Signal Processing Letters,Vol.13, No.2.

[13] Johnson, M.K. et al. "Steganalysis of Recorded Speech". (2005) Conference on Security, Steganography and Watermarking of Multi-media, Vol. 5681, Pages 664-672.

[14] Ozer, H. Activbas, I. et al. "Steganalysis of Audio based on Audio Quality Metrics". (2003) Conference on Security, Steganography and Watermarking of Multimedia, Vol. 5020, Pages 55-66.

[15] Harmsen, J.J. Pearlman, W.A. "Steganalysis of additive noise modelable information Hiding". (2006)

[16] Paliwal, K.K. "Use of temporal correlation between successive frames in a hidden markovmodel based speech recognizer". (1993) IEEE international conference on Acoustics, speech, and signal processing

[17] I. Guyon, J. Weston, S. B, and V. V. (2002) "Gene selection for cancer classification using support vector machines". Mach. Learn., Vol. 46, No. 1-3, pp. 389-422.

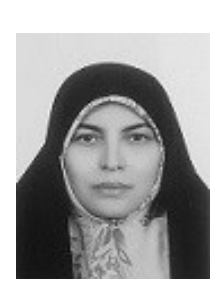

فاطمه اشعرى مدارى كارشناسى و

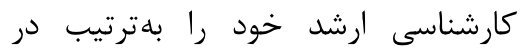

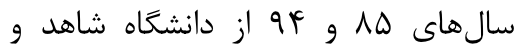
دانشغاه الزهرا در رشته مهندسى كامييوتر

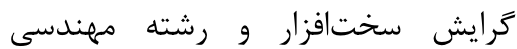
كامييوتر كرايش هوش مصنوعى دريافت كرده است.

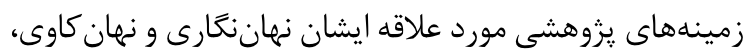
يردازش سيخنال، يردازش صوت و يردازش تصوير است.

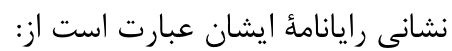

ftashari@gmail.com

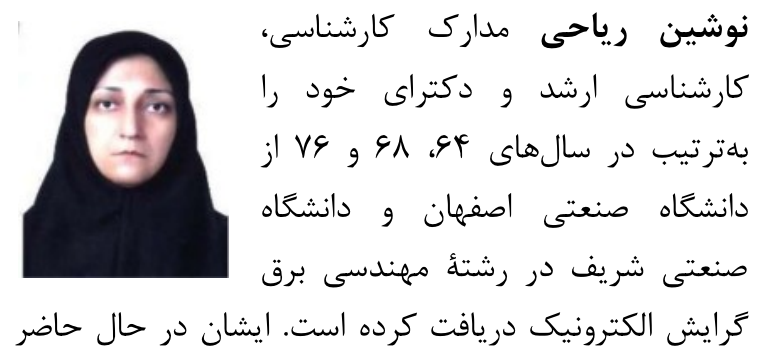

